\title{
Ultrastructure of euspermatozoa and paraspermatozoa in the marine gastropod Adelomelon beckii (Caenogastropoda, Volutidae)
}

\author{
Florencia Arrighetti · Juliana Giménez
}

Received: 10 July 2009 / Revised: 24 November 2009 / Accepted: 26 November 2009 / Published online: 10 December 2009

(C) Springer-Verlag and AWI 2009

\begin{abstract}
The sperm morphology of Adelomelon beckii is described by optical and transmission electron microscopy. Both euspermatozoa and paraspermatozoa were found in the specimens studied. Euspermatozoa are filiform and have an elongate nucleus capped by an acrosome. A small basal plate lies between the base of the acrosome and the nucleus. The mid-piece consists of U-shaped mitochondria wrapped helically around the central axoneme. A dense annulus at the junction of the mid-piece and glycogen piece is found, ending in a short end-piece, composed of the axoneme surrounded by a plasma membrane. Two types of paraspermatozoa are found, both vermiform but differing internally with respect to the disposition and number of axonemes, as well as to the types of secretory vesicles. We suggest the use of paraspermatozoa as a systematic character to reveal phylogenetic relationships in this family.
\end{abstract}

Keywords Sperm ultrastructure · Parasperm · Giant snail $\cdot$ Reproduction $\cdot$ Mollusca

Communicated by H.-D. Franke.

F. Arrighetti · J. Giménez $(\bowtie)$

CONICET Laboratorio de Invertebrados I,

DBBE. Facultad de Ciencias Exactas y Naturales,

Universidad de Buenos Aires, Buenos Aires, Argentina

e-mail: jgimenez@bg.fcen.uba.ar

F. Arrighetti · J. Giménez

CONICET Museo Argentino de Ciencias Naturales

"B. Rivadavia", Av. Ángel Gallardo 470,

Buenos Aires, Argentina

\section{Introduction}

Traditionally prosobranch sperm have been classified as typical or atypical depending on their capacity of fertilization. Healy and Jamieson (1981) proposed the terms euspermatozoa (typical) for those that contain genetic material and are capable of fertilization, and paraspermatozoa (atypical) for those lacking genetic material and being incapable of fertilization. The paraspermatozoa in some species are multifunctional (Hodgson 1997). The morphological diversity of both forms is an important tool that has been utilized for taxonomic and phylogenetic studies in molluscs (Koike 1985; Healy 1983, 1988a). The systematic position of some groups is based on sperm morphology (Healy 1988a, 1996a; Ponder and Lindberg 1997; Ponder et al. 2007).

Adelomelon beckii (Broderip, 1836) is one of the largest molluscan benthic carnivores, inhabiting sandy bottoms (40 and $70 \mathrm{~m}$ in depth) in the eastern south Atlantic coast. This species as well as some others of the family, is commercially exploited and recently detailed studies have been undertaken on its reproductive biology (Arrighetti 2009). The ultrastructure of eu- and paraspermatozoa of some species of the family Volutidae has also been described (Giménez et al. 2008; Zabala et al. 2009). However, a detailed description of both types of sperm has not been reported at ultrastructural level for Adelomelon beckii, except for some preliminary results on euspermatozoa (Giménez et al. 2009).

The purpose of the present paper is to provide a detailed description of the ultrastructure of euand paraspermatozoa in a member of the Volutidae, Adelomelon beckii (Broderip, 1833). Results are compared with those on other neogastropods, especially other volutids. 


\section{Materials and methods}

Reproductively mature male and female Adelomelon beckii (Broderip, 1836) (Volutidae, Caenogastropoda) were obtained from 30 to $50 \mathrm{~m}$ depth through commercial fishing outlets at Mar del Plata Harbour $\left(57^{\circ} 37^{\prime} \mathrm{W}\right.$, $38^{\circ} 20^{\prime} \mathrm{S}$ ) from September to December 2005. After shell removal, a smear of the interior part of the bursa copulatrix (where the male deposits its sperm during copulation) of each female $(N=31)$ was examined microscopically. For males, pieces of the testis $\left(9 \mathrm{~mm}^{3}\right)$ were fixed in Bouin's aqueous solution, dehydrated in a graded ethanol series and embedded in resin (Leica Histoplast) for light microscopy. Serial sections $(5 \mu \mathrm{m}$ thick) were stained with a hematoxylin-eosin and periodic acid Schiff reaction (PAS). Small pieces of testes were also fixed in $2.5 \%$ glutaraldehyde in $0.1 \mathrm{M}$ sodium phosphate buffer containing $0.1 \% \mathrm{CaCl}_{2}$ for $4 \mathrm{~h}$ at $4^{\circ} \mathrm{C}$. Tissues were then washed in phosphate buffer. Subsequently, the tissue pieces were placed in a $1 \%$ solution of osmium tetroxide (in $0.1 \mathrm{M}$ cacodylate) for $1.5 \mathrm{~h}$ and again washed in buffer. Tissues were dehydrated using an ascending series of ethanols (from 20\% to absolute ethanol), then placed in a 1:1 ethanol:propylene oxide solution for $15 \mathrm{~min}$, and finally embedded in Araldite resin. Ultrathin sections, using either a Reichert or an LKB IV ultramicrotome, were stained with uranyl acetate and lead citrate. All sections were examined and photographed using Zeiss (Oberkochen, Germany) EM 109T, Hitachi 300 and Jeol 1,010 transmission electron microscopes operated at $75-80 \mathrm{kV}$. Total sperm lengths ( $N=10, n=15$ per male) were determined by viewing and photographing tissue squashes using a Zeiss Axiostar light microscope.

\section{Results}

\section{Euspermatozoon}

The euspermatozoa are filiform and composed of an anterior acrosomal complex, nucleus, mid-piece, glycogen piece and end-piece.

The acrosomal complex is elongated and consists of an acrosomal vesicle, an axial rod and a basal plate (Fig. 1a, f). Apically, the plasma membrane of the acrosomal vesicle forms an apical bleb with a rounded shape. The acrosomal vesicle is invaginated posteriorly and constricted anteriorly (Fig. 1b-e). An axial rod lies within the posterior invagination (Fig. 1d). A basal plate is situated between the base of the acrosomal vesicle and the nucleus. In the basal region of the acrosome, there is an accessory membrane, parallel to the plasma membrane (Fig. 1f). Transverse sections of the acrosomal complex show its conical form $(0.43 \mu \mathrm{m}$ in diameter anteriorly to $2.14 \mu \mathrm{m}$ posteriorly).

The mature nucleus is long and very electron dense (length $26.67 \pm 3.21 \mu \mathrm{m}$ and width $2.30 \pm 0.55 \mu \mathrm{m}$, $n=20$ ) (Fig. 1a, f, g). The nucleus contains a basal invagination that includes a centriolar derivate and the proximal portion of the axoneme (Fig. 2a, b).

The mid-piece consists of the anterior region of the axoneme that is surrounded by a sheath of helically arranged mitochondria (Fig. 2c). From the analysis of longitudinal and transverse sections it appears that each mitochondrial element consists of a bilaminar, U-shaped, outer layer, which is more electron dense than other parts of the mitochondria (Fig. 2c, d).

Posteriorly the annulus complex, which consists of a double electron-dense ring attached to the inner surface of the plasma membrane, separates the mid-piece from a glycogen piece (Fig. 2c). Posterior to the annulus complex, the axoneme is associated with nine longitudinal and nine radiating tracts of dense granules (Fig. 2c-e). The granules of the glycogen piece stain positively with PAS, indicating that the granules contain neutral glycogen-conjugated elements.

Toward the end-piece the glycogen granules gradually disappear and the sperm diameter decreases from $1.7 \pm 0.19 \mu \mathrm{m}$ in the glycogen piece to $0.7 \pm 0.06 \mu \mathrm{m}$ in the end-piece. The last one consists of a continuous $9+2$ microtubular pattern axoneme surrounded by a plasma membrane (Fig. 2f).

\section{Paraspermatozoa}

The paraspermatozoa of Adelomelon beckii are vermiform and $75.7 \pm 3.2 \mu \mathrm{m}$ in length. The apex regions are bunched in contact with the periphery of the tubule (Fig. 3a). Two morphological types can be recognized, differing in the number of internal axonemes. In the first type, the axonemes in the apical region of the paraspermatozoon terminate in basal bodies with rootlets that are embedded in an electron-dense cap (Fig. 3b, c). In the main body of the paraspermatozoa, the axonemes $(22 \pm 3 ; n=15)$ are distributed peripherally (Fig. 3d, e). In addition, numerous very electron-dense vesicles lie close to, or in contact with, the inner surface of the plasma membrane. Occasionally, large round vesicles of low to moderate electron density (putative lipid vesicles), numerous less electron-dense small vesicles and often elongate mitochondria are observed (Fig. 3d, e).

The second type of paraspermatozoon shows 47 axonemes and 10 possible centriolar rootlets close to the apical region (Fig. 3f, g). The main body consists of $70 \pm 5$ axonemes $(n=13)$, distributed peripherally and in the core region of the cell (Fig. 3h). 

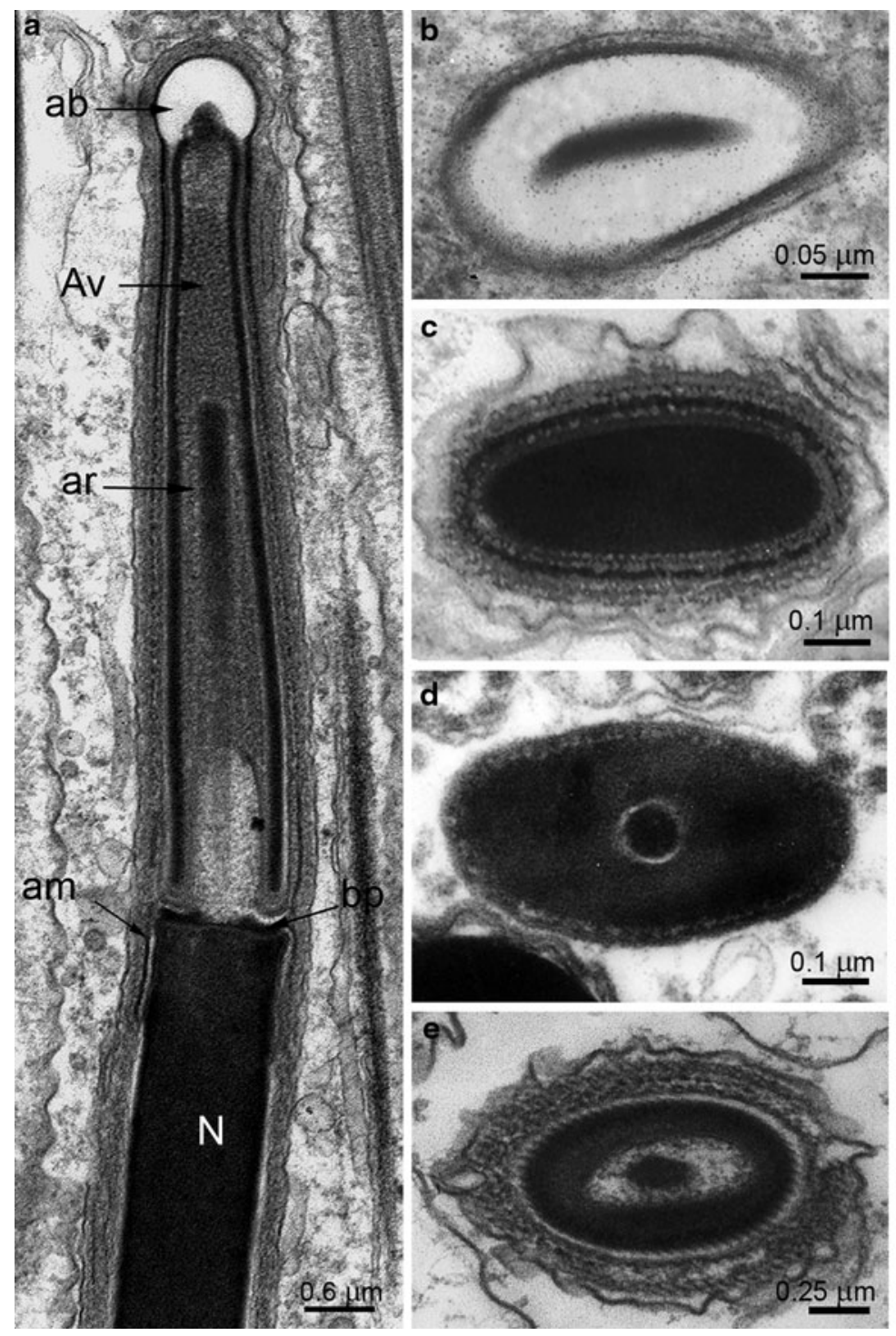

In the bursa copulatrix of females both cell types were observed, and paraspermatozoa were observed actively moving for the entire period.

\section{Discussion}

\section{Euspermatozoon}

As to the ultrastructure of euspermatozoa, two groups of caenogastropods can be distinguished (Healy 1996a). The structure of the euspermatozoa of Adelomelon beckii places this species in group 2 . invagination and the axial rod material. $\mathbf{f}$ LS through the basal portion of the acrosomal complex, showing the junction with the nucleus. Note the basal plate and the accessory membrane. $g$ TS of the nucleus. $a b$ Apical bleb, $a r$ axial rod material, $A v$ acrosomal vesicle, $a m$ accessory membrane, $b p$ basal plate, $N$ nucleus

The acrosome structure is similar to those found in other

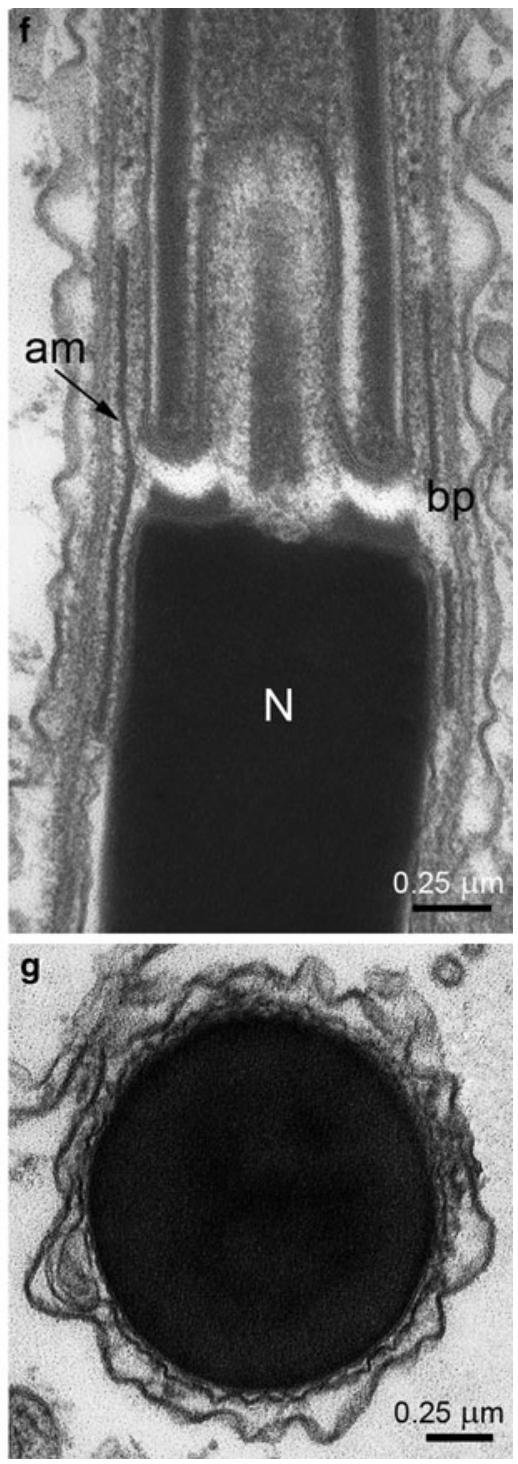

mesogastropods and neogastropods, except for the constriction present in the invagination of the acrosomal vesicle. This also was found in Zidona dufresnei and Adelomelon ancilla (Giménez et al. 2008; Zabala et al. 2009), both belonging to the subfamily Zidoninae.

The structure of the nucleus, with a basal invagination where the axoneme is inserted, is similar to that in most mesogastropods (Healy 1982, 1986a, b, 1994, 1996b) and some neogastropods (Giménez et al. 2008; Zabala et al. 2009).

In other species of the superfamily Muricoidea (West 1978; Jaramillo et al. 1986; Gallardo and Garrido 1989; 

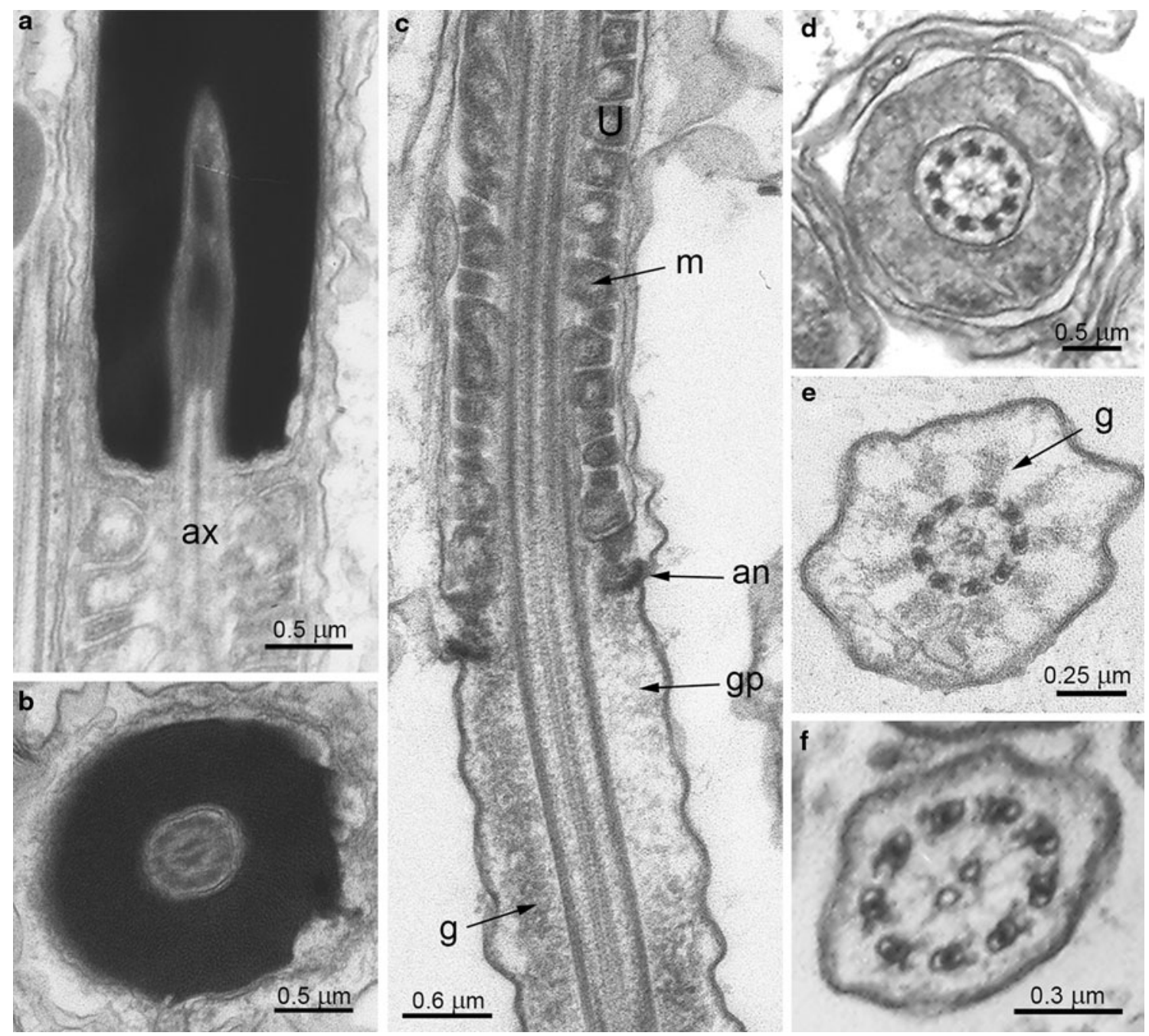

Fig. 2 Euspermatozoa of Adelomelon beckii. a LS of the junction of the nucleus (showing invagination and centriole/axoneme insertion) and anterior portion of mid-piece. $\mathbf{b}$ TS of the nucleus with centriolar fossa. $\mathbf{c}$ LS of the junction of mid-piece and glycogen piece. Note helical mid-piece elements (defined by dense U-shaped profiles) and the

Giménez et al. 2008; Zabala et al. 2009), the mid-piece is formed by mitochondrial elements helically arranged around the axoneme. In A. beckii, in particular, the outer layer of each mitochondrial element is very electron dense, with a U-shape profile in transverse section, coinciding with the other volutids studied (Giménez et al. 2008; Zabala et al. 2009).

The annulus of $A$. beckii is similar to that found in other neogastropods and in many neotaenioglossans (BucklandNicks et al. 1982a, b; Koike 1985; Healy 1986a, 1988b; Healy and Jamieson 1993) and differs from the single ring annulus observed in basal caenogastropods (Healy 1982, 1983). The glycogen piece and the end-piece do not differ from the configurations shown in other caenogastropods (Koike 1985). annular complex. d-f TS through the mid-piece until the end-piece. e TS of the glycogen piece. Note the putative granules. $f$ TS of the endpiece, the axoneme is close to the membrane. an Annulus, $a x$ axoneme, $g$ putative glycogen granules, $m$ mitochondrion, $U \mathrm{U}$-shaped defining edge of mitochondrial element

\section{Paraspermatozoa}

Our observations confirm the presence of two types of parasperm, a phenomenon that has previously been demonstrated in five caenogastropod families (Nishiwaki 1964; Buckland-Nicks et al. 1982a, b; Healy 1986b; Giménez et al. 2008). Buckland-Nicks et al. (1982a) differentiated two types of vermiform paraspermatozoa in the ranellid Fusitriton oregonensis (Redfield, 1848), a bulkier 'carrier' type, which bears numerous attached euspermatozoa and contains vary large-dense vesicles and approximately 112 axonemes, and a smaller type, the 'lancet', which never physically associates with euspermatozoa and contains small vesicles and only 16 axonemes. The first type is similar to the 'lancet type' while the second type is similar to 


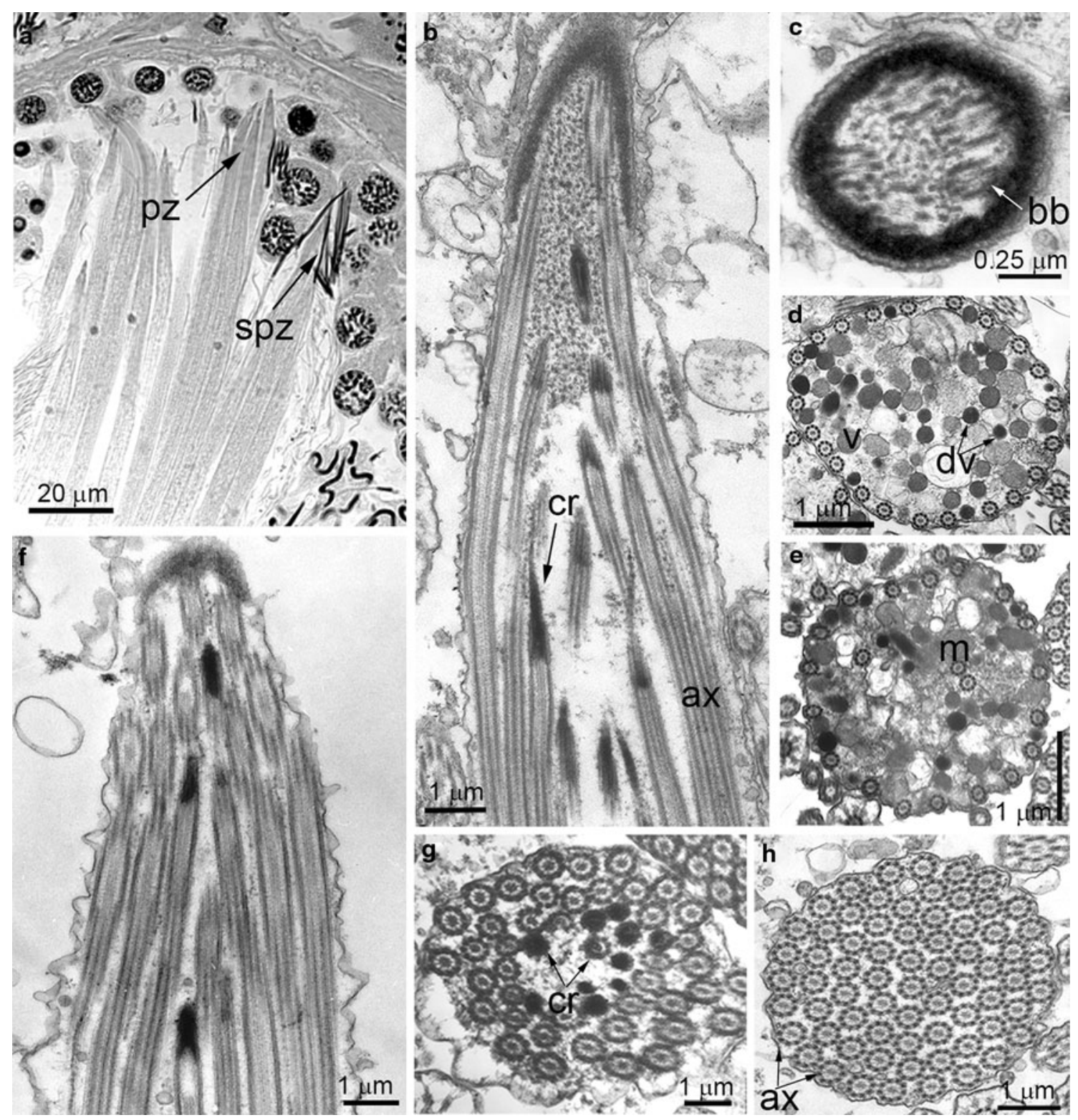

Fig. 3 Paraspermatozoa of Adelomelon beckii. a Detail of cohorts of paraspermatozoa showing vermiform shape. Paraspermatozoa Type 1: b LS of the apical region showing electron-dense material as a cap. Axonemes are ending in the granular material beneath the dense cap. c TS through the apex showing sheath of granular material enclosing axonemes and basal body/centriolar complexes. d, e TS of the main body region showing the 22 peripheral axonemes, dense vesicles, lessdense vesicles, some axonemes and a mitochondrion embedded in a

the 'carrier type' described by Buckland-Nicks et al. (1982b). We did not observe any physical association of euspermatozoa and paraspermatozoa in the testis and in the sperm duct of $A$. beckii.

We suggest the use of paraspermatozoa characteristics as an important taxonomic tool in the family Volutidae. The number of axonemes differs markedly among the members of this family: $Z$. dufresnei has 16 axonemes in the paraspermatozoa of type 1 and 28 axonemes in those of type 2 dense matrix. e TS of the body region showing 22 peripheral axonemes, dense vesicles, less-dense vesicles and mitochondria. Paraspermatozoa Type 2: f LS of the apical region showing electron-dense material as a cap. $\mathbf{g}$ TS near apex of cell showing 47 axonemes and 10 centriolar rootlets. $\mathbf{h}$ TS anterior region of cell showing $70(9+2)$ axonemes. $a x$ Axoneme(s), $b b$ basal body, $c r$ centriolar rootlet, $\mathrm{d} v$ dense vesicles, $m$ mitochondrion, $p z$ paraspermatozoa, $s p z$ spermatozoa, $v$ less-dense vesicles

(Giménez et al. 2008), while A. beckii has 22 and 70 axonemes, respectively.

The presence of very active paraspermatozoa and active euspermatozoa in the bursa copulatrix of females was observed in vivo by light microscopy. Further studies are necessary to confirm a possible association of the two cell types in the bursa copulatrix after copulation. Arrighetti (2009) observed the presence of live euspermatozoa and paraspermatozoa in the bursa copulatrix. Our observation 
could give us an idea about the function of these structures in the bursa copulatrix. Buckland-Nicks (1998) suggest paraspermatozoa may be involved in creating a hostile prefertilization environment for rival sperm. We propose that paraspermatozoa could also contribute to the movement of the euspermatozoa, facilitating their motility in the female after copulation.

Acknowledgments This work was partially supported by CONICET PIP 5301, PIP 2788 and UBACyT X-171. Some pictures were taken by Kerstin Beyer with the TEM of the Alfred Wegener Institute, Germany.

\section{References}

Arrighetti F (2009) Reproduction, ultrastructure and growth of the giant snail Adelomelon beckii (Broderip 1836) off Mar del Plata, Argentina. PhD Thesis. Universidad de Buenos Aires, Argentina

Buckland-Nicks J (1998) Prosobranch parasperm: sterile germ cells that promote paternity? Micron 29:267-280

Buckland-Nicks JA, Williams D, Chia FS, Fontaine A (1982a) The fine structure of the polymorphic spermatozoa of Fusitriton oregonensis (Mollusca: Gastropoda), with notes on the cytochemistry of the internal secretions. Cell Tissue Res 227:235-255

Buckland-Nicks JA, Williams D, Chia FS, Fontaine A (1982b) Studies on the polymorphic spermatozoa of a marine snail. I-Genesis of the apyrene sperm. Biol Cell 44:305-314

Gallardo C, Garrido O (1989) Spermiogenesis and sperm morphology in the marine gastropod Nucella crassilabrum with an account of morphometric patterns of spermatozoa variation in the family Muricidae. Invertebr Reprod Dev 15:163-170

Giménez J, Healy JM, Hermida GN, Lo Nostro FL, Penchaszadeh PE (2008) Ultrastructure and potential taxonomic importance of euspermatozoa and paraspermatozoa in the volutid gastropods Zidona dufresnei and Provocator mirabilis (Caenogastropoda, Mollusca). Zoomorphol 127:161-173

Giménez J, Arrighetti F, Teso V, Hermida GN, Zabala S, Penchaszadeh PE (2009) Sperm morphology of two marine neogastropods from the southwestern Atlantic Ocean (Caenogastropoda: Volutidae and Olividae). Nautilus 123:166-171

Healy JM (1982) An ultrastructural examination of developing and mature euspermatozoa in Pyrazus ebeninus (Mollusca, Gastropoda, Potamididae). Zoomorphol 100:157-175

Healy JM (1983) Ultrastructure of euspermatozoa of cerithiacean gastropods (Prosobranchia: Mesogastropoda). J Morphol 178:57-75

Healy JM (1986a) An ultrastructural study of euspermatozoa, paraspermatozoa and nurse cells of the cowrie Cypraea errones (Gastropoda, Prosobranchia, Cypraeidae). J Moll Stud 52:125-137
Healy JM (1986b) Euspermatozoa and paraspermatozoa of the relict cerithiacean gastropod, Campanile symbolicum (Prosobranchia, Mesogastropoda). Helgol Meeresunter 40:201-218

Healy JM (1988a) Sperm morphology and its systematic importance in the Gastropoda. In: Ponder WF (ed) Prosobranch phylogeny. Malacol Rev (Suppl) 4:251-266

Healy JM (1988b) The ultrastructure of spermatozoa and spermiogenesis in pyramidellid gastropods, and its systematic importance. Helgol Meeresunter 42:303-328

Healy JM (1994) Euspermatozoa in the marine gastropod Epitonium sp. (Epitoniidae, janthinoidea) with a discussion of janthioidean relationships as indicated by sperm ultrastructure. Invert Reprod Dev 26:229-235

Healy JM (1996a) Molluscan sperm ultrastructure: correlation with taxonomic units within the Gastropoda, Cephalopoda and Bivalvia. In: Taylor J (ed) Origin and evolutionary radiation of the mollusca. Oxford University Press, Oxford, pp 99-113

Healy JM (1996b) Euspermatozoan ultrastructure in Bembicium auratum (Gastropoda): comparison with other caenogastropods especially other Littorinidae. J Moll Stud 62:57-63

Healy JM, Jamieson BGM (1981) An ultrastructural examination of developing and mature paraspermatozoa in Pyrazus ebeninus (Mollusca, Gasteropoda, Potamididae). Zoomorphol 98:101-119

Healy JM, Jamieson BGM (1993) Euspermatozoa, paraspermatozoa and spermatozeugmata of Littorina (Palustorina) articulata (Prosobranchia: Caenogastropoda) with special reference to the pseudotrich. Acta Zool 74:321-330

Hodgson AN (1997) Paraspermiogenesis in gastropod molluscs. Invertebr Reprod Dev 31:31-38

Jaramillo R, Garrido O, Jorquera B (1986) Ultrastructural analysis of spermiogenesis and sperm morphology in Chorus giganteus (Lesson, 1829) (Prosobranchia: Muricidae). Veliger 29:217-225

Koike K (1985) Comparative ultrastructural studies on the spermatozoa of the Prosobranchia (Mollusca: Gastropoda). Sci Rep Fac Educ Gunma Univ 34:33-153

Nishiwaki S (1964) Phylogenetical study on the type of the dimorphic spermatozoa in Prosobranchia. Sci Rep Tokyo Kyoiku Daigaku Sect B 11:237-275

Ponder W, Lindberg DR (1997) Towards a phylogeny of gastropod molluscs: an analysis using morphological characters. Zool J Linn Soc 119:83-265

Ponder WF, Colgan DJ, Healy JM, Nützel A, Simone RLL, Strong EE (2007) Caenogastropoda. In: Ponder WF, Lindberg DL (eds) Molluscan phylogeny. University of California Press, Los Angeles, pp 331-383

West DL (1978) Reproductive biology of Colus stimpsoni (Prosobranchia: Buccinidae). 2. Spermiogenesis. Veliger 21:1-9

Zabala S, Hermida GN, Giménez J (2009) Ultrastructure of euspermatozoa and paraspermatozoa in the volutid snail Adelomelon ancilla (Mollusca: Caenogastropoda). Helgol Mar Res 63:181-188 